\title{
Concentration of Critical Events over the Life Course and Life Satisfaction later in life
}

\author{
Chiara L. Comolli*, University of Lausanne \\ Danilo Bolano, Bocconi University \\ Laura Bernardi, University of Lausanne \\ Marieke Voorpostel, FORS \\ *corresponding author: chiara.comolli@unil.ch
}

\begin{abstract}
Critical events are occurrences that create turning points, disrupt individuals' life courses and affect wellbeing. Here, we investigate how the co-occurrence of critical events and, in particular, the spacing in time of events across the life course influences life satisfaction in later life. We argue that life phases densely populated of critical events may translate into an acute resource drain affecting wellbeing in long term more strongly than if the same events were sparsely distributed. We use retrospective biographical information on critical events in family, work, health and residential trajectories in Switzerland to construct a life course Concentration Index of events based on the number, the time-lag between the occurrences and the number of life domains involved. Our results show that the higher is the concentration in time of critical events, the stronger will be their negative long-term effect on wellbeing, net of socio-demographic characteristics, of the total number of events ever experienced and of the time since the last event. Furthermore, such negative effect is even stronger if the person experienced periods dense of events during midlife and older adulthood than during youth or early adulthood.
\end{abstract}

Keywords: subjective wellbeing; critical events; concentration; life course; life stages

\section{Acknowledgments}

This work was supported by the Swiss National Centre of Competence in Research "LIVES Overcoming vulnerability: Life course perspectives", which is financed by the Swiss National Science Foundation (SNSF; 51NF40-160590). The authors are grateful to the SNSF for financial assistance. This study has been realized using the data collected by the Swiss Household Panel (SHP), which is based at FORS-the Swiss Centre of Expertise in the Social Sciences. The project is supported by the Swiss National Science Foundation. Danilo Bolano gratefully acknowledge financial support from project DisCont - Discontinuities in Household and Family Formation (PI: Billari - ERC Grant no. 694262). The authors would like to thank Daria Mendola, Annalisa Busetta and Giovanni Luca Lo Magno for the precious discussions aimed at adapting their own concentration index to the purposes of this paper. 


\section{Introduction}

Critical events or stressors induce readjustments in people's behaviours and routine (Dohrenwend, 2006; Park, 2010) or adaptation to new social roles (Hopson and Adams, 1976). They do not necessarily represent traumas or negative events stricto sensu, but events that force individuals to adjust to new circumstances (Luhmann et al., 2012), like becoming a parent or going into retirement. In this study, we investigate how the co-occurrence of critical events and, in particular, the spacing in time of events across the life course influences life satisfaction in later life introducing a novel indicator of events' concentration.

A voluminous and long-standing literature documents the extent to which subjective wellbeing (SWB) is influenced by critical events (Dohrenwend and Dohrenwend, 1974; Yap et al., 2014; Hentschel et al., 2017). Most existing studies focus on the wellbeing consequences of one event in isolation or multiple events in one given life domain (Booker and Saker, 2011; Demey et al., 2014). Yet, a central principle of life course theory is the multidimensionality of biographies: Life domains are interdependent and life events do not occur in isolation, but in a configuration of related trajectories (Diewald and Mayer, 2009). Critical events from different domains often co-occur (Thomas, 2018), making it difficult to isolate the impact of single events, especially over a lifetime (Seery et al., 2010). Becoming a parent affects not only family life but might have repercussion on work-related or residential decisions, a divorce is usually followed by a residential move (Clark, 2016), while a job loss might lead to a union dissolution (Charles and Stephens, 2004; Sayer et al., 2011). Events could also occur independently but successively within a short timeframe (Thomas, 2018). The focus on single events' responses, although allowing for a deeper investigation of each event's impact, gives a decontextualized view of each event and obscures the fact that the accumulation and concentration of multiple events may have important additional effects (Thomas, 2018; Comolli et al., 2021). In addition, stress proliferation theory emphasizes that the exposure to one stressor may lead to exposure to other stressors over time, resulting in moments when people's lives become crowded of critical events, with the potential for life course disruption (Pearlin et al., 1981; Pearlin, 2010).

Drawing on life course and stress proliferation theories, we argue that the exposure to critical events has stronger long-term effects when such occurrences are experienced closer together, possibly destabilizing multiple life spheres in a short period of time. We put particular emphasis on the effect of event concentration over time. By concentration of events we mean their distribution over time, that is the fact that events may occur in a relatively shorter or longer time window and over multiple life domains. In this vein, we introduce a life course index of concentrations events based on the number, the time-lag between the occurrences and the number of life domains involved.

This study investigates the long-term effect of concentration of events over the life course on SWB. Few longitudinal studies have compared the impact of given life events on SWB in the context of a wide range of other events. Most of such studies focus on the linked psychological mechanisms of 
anticipation or adaptation (Luhmann and Eid, 2009; Voelkle et al., 2013; Anusic et al., 2014; Luhmann et al., 2014). The assessment of cumulative adversity typically involves just the counts of negative events experienced over a given period of time (Wheaton and Clarke, 2003; Seery et al., 2010; Frijters et al., 2020). The extent to which the different distribution of critical life course events across time has differentiated long-term effects remains largely unmeasured.

We argue that life phases densely populated of critical events may cause an extremely acute resource drain and affect wellbeing more strongly than whether the same events were sparsely distributed over the life course. To this end, we assume that even transitions that are normally benign (e.g. childbirth) may become stressful if they take place in close temporal proximity with multiple other transitions (Pearlin, 2010). Building on a novel indicator of the distribution of events in individuals' history, we are able to assess more rigorously the impact of lifetime concentration of critical events on SWB later on in life (McMahon et al., 2003; Seery et al., 2010).

We exploit the complete retrospective biographical information on life events in multiple domains (family, work, health and residence) collected in the 2013 wave of the Swiss Household Panel (SHP) to investigate lifelong association between the concentration of events over the life course and life satisfaction later on in life. We adapt the Longitudinal Poverty Index (LPI), first developed by Mendola et al. (2011) and Mendola and Busetta (2012) and later re-contextualized to study the distribution of unemployment spells (as Joblessness Persistence Index (JPI), see Busetta et al., 2019), to construct an index of critical events' time distribution over the life course, our Concentration Index (CI). Our CI innovatively takes into account not only, as in previous studies, the overall number of events ever experienced, but also the time between them and the number of different domains involved. The present study contributes to the life course and wellbeing literatures both with an original assessment of how the concentration of critical events during the life course affects SWB later in life, and empirically investigating whether the relationship between the concentration of events and SWB holds in all phases of the adult life course (youth and early adulthood, midlife and older adulthood).

\section{Background}

Critical events are occurrences of sufficient magnitude that challenge the adaptive capacities of people (Pearlin, 2010: 208), bringing about a readjustment of individuals' activities and a major change in status and/or social roles (Dohrenwend et al., 1978; Dohrenwend, 2006). Critical life events are distinct from short-term fluctuations in life circumstances (e.g., income variations) because the latter do not involve a status or role change. Critical life events are also distinct from developmental transitions (e.g., to adulthood) because the latter unfold over longer periods and are not time discrete (Luhmann et al., 2012). A rich literature documents that critical life events are related to wellbeing (Yap et al., 2014; Hentschel et al., 2017). Most cross-sectional studies yet support the notion that people adapt quickly to 
life changes (Brickman and Campbell, 1971) and that most life events affect wellbeing only in the shortterm (Lykken and Tellegen, 1996; Diener et al., 2006). In contrast, more recent longitudinal studies show that the effects of major life events on wellbeing can persist over several years (Lucas, 2007). Most studies on critical life events and SWB focus on one type of event at the time (Booker and Saker, 2011; Demey et al., 2014). Such studies show that a longer duration or persistence of some events or statuses (e.g. joblessness) generally results in greater reduction of wellbeing (Lucas et al., 2004). The recurrence of some types of events has been shown to have cumulative negative effects on wellbeing (Clark et al., 2008; Luhmann and Eid, 2009; Frikters et al., 2011). In unemployment research particularly, the timing and duration of events has been shown to affect mental health and wellbeing even in the long-term and beyond more proximal determinants of wellbeing outcomes (Wheaton and Reid, 2008; Ponomarenko, 2016).

Treating each (kind of) event separately undoubtedly allows research to focus more deeply into each event's impact on the life course. Yet, this gives a decontextualized, partial view (Thomas, 2018). Events vary by valence (positive or negative) ${ }^{1}$ and domain (e.g., family, health, work) but also in duration, number, timing and dispersion over the life-course (Lindeboom et al., 2002). In their metaanalysis, Luhmann and colleagues (2012) find that an important confounder in many longitudinal studies of the relationship between a given critical life event and SWB is the differential ascertainment and handling of other concurrent events. The stress proliferation literature highlights that exposure to one stressor may lead to exposure to other stressors, exacerbating the negative consequences for wellbeing (O'Rand 1996; Thoits 2010). ${ }^{2}$ Few studies in social psychology investigated how clusters of adversities differ from single events (Kessler et al., 1997; Raposa et al., 2014). Although with a varying strength depending on the type of events that are clustered together, the effect of single events results considerably attenuated once the clustering of multiple adversities is considered. Moreover, it appears that the effects of concurrent critical events on health and wellbeing is multiplicative and not simply additive (Kessler et al., 1997). These studies also show the presence of cumulative effects over the life course: clusters of early childhood adversities predict later experience of stressful events which result in a compounded negative effect on young adults' mental health (Raposa et al., 2014).

Critical events can be, and often are, coupled together. There are events that prompt another event, such as a residential move following retirement, divorce or childbirth (Clark, 2016; South, Crowder, \& Trent, 1998; Weitzman, 1985). Economic strain and family conflict often follow involuntary job loss (Pearlin et al. 1981) so that a job loss can lead to a union dissolution (Charles \& Stephens, 2004; Sayer, Allison, England, \& Kangas, 2011). Such critical events could also occur independently but successively within a given short timeframe.

\footnotetext{
${ }^{1}$ Although occurrences such as marriage or childbirth tend to be identified as positive and others like divorce or job loss as negative, identifying a priori the valence of events can be challenging (Kettlewell et al., 2020). For instance, first, despite the positive valence of marriage, Holmes and Rahe (1967) identify marriage as the sixth most stressful event in the life course; second, the issue of whether childbirth increases parents' life satisfaction or not has been debated at length (Aassve et al., 2012; Myrskyla and Margolis, 2014).

${ }^{2}$ This resembles the ideas of a chain reaction within a life trajectory (Wheaton \& Gotlib, 1997), of clusters of adversities (Kessler et al., 1997) or "cascade of instability," in which one event prompts another event (Thomas 2018).
} 
Co-occurring critical events can belong to the same or to different life domains, and they can have the same or the opposite valence. Suh and colleagues (1996) show that "good" and "bad" events are actually more likely to occur together than apart in the course of life. Individuals who experience more negative events also tend to experience more positive events, and events of opposite valence also tend to cooccur close in time within the life course of each individual. Engaging with the literature on the heterogeneous effects of "good" and "bad" events on SWB goes beyond the scope of this study which considers any kind of critical event as potentially stressful if co-occurring with others, however, it is worthwhile mentioning here that events with opposite valence may theoretically compensate each other in influencing SWB, although the evidence supporting this argument is contradictory. While taken independently, negative and positive events are shown to influence wellbeing asymmetrically, with negative events reducing it and positive events (more weakly) increasing it (Kahneman and Tversky, 1979; Vendrik and Woltjer, 2007; Boyce et al., 2013; De Neve et al., 2018), the evidence on the interplay between "good" and "bad" events is mixed. Positive occurrences seem to buffer the effect of negative events only on some negative psychological outcomes (e.g. stress and depression) but not on positive affect or subjective wellbeing, and only among the most vulnerable individuals who experience a large number of adversities (Reich and Zautra, 1981; Nezlek and Plasko, 2003; Longua et al., 2009). Positive events may also have negative effects if unexpected (Reich and Zautra, 1981).

Few studies have compared the impact of life events on SWB longitudinally in the context of a wide range of other events. Kettlewell et al. (2020) investigate the relative impact of specific events on wellbeing, conditional on the occurrence of other events. The main finding is that some events, like being fired or getting promoted, have little independent effect on wellbeing, while others, like widowhood or childbearing, influence wellbeing even conditional on other events co-occurring. However, Kettlewell and colleagues (2020) do not investigate the effect of overall dispersion of events, as they focus on singling out the impact of each event on wellbeing, net of additional events happening at the same time. In addition, the study focuses on SWB fluctuations in the years (six) around the event and not on long-term effects of the co-occurrence of events.

Seery, Holman and Silver (2010) investigate how lifetime adversity, measured as number of negative events experienced during life (health, finance, relationships, family and work domains), influences life satisfaction. The study demonstrates that that association between lifetime negative events and SWB later on is quadratic following an inverted $U$ shape pattern: individuals who experience an average number of negative events report a higher wellbeing compared to both those who experience a large number and those who experience zero or low adversity. The authors refer to Dienstbier's $(1989,1992)$ theory emphasizing that regular exposure to adverse events followed by adequate recovery periods promote mental toughness development, namely a greater capacity in the future to deal with stressors. The argument of spacing between multiple critical events is thus crucial (Thoits, 1983) but, in Seery et al. (2010), remains untested. 
A recent study by Frijters et al. (2020) investigates the effects of the bunching of negative and positive events on life satisfaction in the short and medium term. As earlier studies, the authors measure concentration of events as the number of occurrences within in a two-year time window. They find that net of selection process and anticipation and adaptation to the events, the greater number of negative events in the last two years the more negative the impact on SWB. The greater the number of the positive events, instead, the lower their joint beneficial effect on life satisfaction.

In the relatively few studies conducted on multiple life events so far, clusters of critical events are generally measured through the simple counting of life events, which is not ideal to measure the distribution over time of co-occurring critical events, especially over a long period of time. Our study instead builds on a novel indicator of individuals' overall history of adversity to more rigorously assess the impact of life-time concentration of critical events on life satisfaction later on (McMahon et al. 2003; Seery et al. 2010). We hypothesise that, beyond the number of total events ever experienced and their recentness, a greater life course concentration of critical events is negatively associated to subjective wellbeing later in life (H1).

We construct an indicator of life course concentration of critical events, the Concentration Index (CI), based on the Joblessness Persistence Index (JPI), presented by Busetta et al. (2019) in the context of life course distribution of unemployment spells. The CI innovatively takes into account not only, as in previous studies, the overall number of events ever experienced but also the time between them and the number of domains involved at each time. Our study is the first to assess how lifetime concentration of critical events in a relatively crowded life course section lowers SWB later in life.

Furthermore, differently from previous studies we acknowledge that the definition of timing of events naturally includes the age at which the events are experienced, as a marker of stage in the life course, or a moment in history (Wheaton and Reid, 2008). A central tenet of life course theory holds that any event occurs in the life course as part of a series of events (Elder, 1999; Mayer, 2009) or as age-graded pattern (Elder et al., 2004). Although people experience events that disrupt the life course in some way and create sometimes unexpected transitions or turning points (Thomas, 2018), some life stages of the life course tend to be characterized by a greater number of events and more normative age-related transitions (Riley \& Riley, 1994; Uhlenberg \& Mueller, 2004). For instance, young adults might move more frequently in relation to education or the entry into the labour market, but they might be more resilient to such critical events compared to older adults because such events are expected and more normative at their age. Clarke and Wheaton (2005) define stages of adulthood based on age-specific problems, goals and transitions. The decade following the end of education, youth, is the "sorting period', characterized by "uncertainty, transience, choice, and turnover in relationships, roles, and jobs" (Clarke and Wheaton, 2005: 271). The authors define the subsequent period, early adulthood, as the 'developmental period' when role commitment and responsibilities expand and long-term life chances are defined, and the following 'midlife period' as the time that combines a stabilizing component derived from earlier investments with still possible new direction to take. Finally, the last stage of 
adulthood, 'later life', is characterized by progressive disengagement from commitment, responsibilities and social roles (Clarke and Wheaton, 2005: 271-272). Voelkle and colleagues (2013) show that the profiles of adjustment to recurrent critical events tends to differ during young adulthood compared to mid-life and older ages. Young adults display a stronger immediate reduction in positive mood in response to unpleasant events compared to older adults, but they also tend to adjust back after recurring events. Older adults display smaller drops initially but maintain the same negative mood response throughout the re-occurrence of unpleasant events. Based on the theoretical appraisal of adulthood stages, the related age distribution of critical events and their potential impact on SWB, we hypothesise that the impact of critical events concentration on subjective wellbeing varies depending on individuals' life phase. In particular, we hypothesise that it might be higher over periods where an individual is normally less at risk of experiencing multiple critical events because of the non-normative character of such unusual concentration (H2).

\section{Data and method}

\section{Data and measures}

Data come from the Swiss Household Panel (SHP), an ongoing rich longitudinal representative survey of households in Switzerland running for 21 waves (1999-2019). In addition to the panel variables, in 2013 the SHP collected complete retrospective information on life events in various domains. In practice, the respondents completed a roster (a life calendar) listing the events experienced since birth. This allowed us to reconstruct entire biographies on family life, work, health and residential mobility ${ }^{3}$ and to construct a measure of lifelong concentration of critical events. In particular, we will consider the following as critical events. In the family domain: parental marriage/union, parental divorce/separation or remarriage, birth of siblings, death of parents/relatives, own marriage/union, separation/divorce, childbirth or loss of a child. In the work domain: entry into full-time work (from education, unemployment, or part-time), entry and exit from unemployment, retirement. In the health domain: any accident, illness, operation and mental health issues. Finally, we count any residential moves within Switzerland or from/to abroad. Table A.1 in the Appendix provides a detailed distribution of such events.

We merge such measure with the information on our dependent variable, wellbeing, coming from subsequent panel waves. We measure subjective wellbeing with life satisfaction, which is reported on a scale from 0 (not at all satisfied) to 10 (completely satisfied) and the question formulation is "In general, how satisfied are you with your life if 0 means "not at all satisfied" and 10 means "completely satisfied"?".

\footnotetext{
${ }^{3}$ In the case of health and family domains, respondents have to identify themselves what qualifies as an important event. For each year, the respondent could report multiple family life events, multiple residential moves and/or multiple health issues. For the working trajectory, only one event (e.g., job loss) per year is recorded.
} 
From the initial sample of 6,090 individuals who filled in the biographical life calendar, we select men and women in the age range 15-65 at completion of the life calendar (5,793 ids) and among them, we keep those who responded to the life satisfaction question in the subsequent waves (the earliest measure in 2014-2017) and drop the few (38 ids) with missing data on basic demographic information (getting to 3,493 ids). Finally, we keep individuals who experienced at least two events in their life (the majority of respondents did) because, by definition, the concentration of events cannot be measured with zero or one event only. The final sample is composed of 3,192 individuals (1,444 men and 1,748 women) who are retrospectively observed, the longest for 51 years. The resulting final age range in the sample is 1865. Summary statistics are presented in Table A.2.

\section{Concentration Index}

Our main independent variable, the life course Concentration Index (CI), measures the time distance between critical events ever experienced. To this end, we use a weighted sum of all the distances between the events. The CI is adapted from the Longitudinal Poverty Index (LPI) developed by Mendola et al. (2011) and Mendola and Busetta (2012) to measure the persistence of poverty. The LPI index has been recently applied outside the context of chronic poverty to measure the persistency of joblessness (Busetta et al. 2019). The main difference between previous versions of the index and ours here, is that we use different types of events, while previous specifications focused on only one at the time (poverty or unemployment spells).

At each year of the life history, we count how many critical events happened and in which of the four life domains (family, work, health and residence). Due to the nature of the data, we do not have the exact date of the event but only the year when it occurred so we might end up having multiple critical events that happened simultaneously, i.e., in the same year. We need to distinguish then between 'events', and 'episodes'. By 'events' we mean the years (age) in which there is at least one critical life event reported. By 'episodes' we mean each single occurrence, counting multiple occurrences per year. In other words, for each event (year when at least one occurrence was reported), we count how many occurrences actually happened.

Equation (1) presents our Concentration Index (CI):

$$
C I_{i}=\frac{\sum_{j, k}\left(d_{j k}+1\right)^{-1} w_{j k}}{\sum_{g=1}^{T-1} \frac{g}{T-g+1}}, j>k
$$

The term $d_{j k}$ in Eq. (1) represents the time span between any pairs of 'events' (i.e., the number of years between any pair $j, k$ ). For instance, let's say that one individual in our sample reported four critical events over the life course: marriage and residential move both at age of 20, childbearing at age of 25 and a job loss at age 30. Since marriage and residential move happened "simultaneously" (i.e., in the same year) and we cannot distinguish which one happened first, we consider them as a unique 'event' 
so we end up with three pairs of 'events': i) marriage and moving; ii) childbearing; iii) job loss. We calculate the (yearly) distance between each pair of events as follows: 1) distance between marriage/moving and childbearing $\left.\left(\mathrm{d}_{12}=5\right), 2\right)$ distance between marriage/moving and job loss $\left(\mathrm{d}_{13}=\right.$ $10), 3)$ distance and between childbearing and job loss $\left(\mathrm{d}_{23}=5\right)$. For each pairs of events, the weight $\mathrm{W}_{\mathrm{jk}}{ }^{4}$ allows to take into account that multiple occurrences might happen "simultaneously" as in our previous example. The weight is constructed to give more importance to pairs of 'events' in which multiple episodes took place. For each distance $d$, i.e., for each pairs of events $j, k$, the weight is calculated as the average share of episodes happening in each year. The weight is then equal to 1 for a pair of events in which in both years, the observed maximum number of episodes happened (four or more in our sample ${ }^{5}$ ), while it is equal to 0.5 for instance when for a pair of events in which in both years, half of the maximum number of episodes happened. In other words, pairs of events that happened in very crowded years will receive a higher weight.

In our example above, we would have for the first distance $\mathrm{d}_{12}$ two episodes (marriage and moving) out of a maximum of four in the first year and one (childbearing) out of four in the second year. The associated weight would then be: $\mathrm{w}_{12}=\frac{\frac{2}{4}+\frac{1}{4}}{2}=0.375$. Similarly, for the other pairs of episodes we will have: $\mathrm{w}_{13}=\frac{\frac{2}{4}+\frac{1}{4}}{2}=0.375$ and $\mathrm{w}_{23}=\frac{\frac{1}{4}+\frac{1}{4}}{2}=0.25$.

Finally, $\mathrm{T}$ is the total number of years each person is present in the data. The denominator represents the maximum concentration possible for an individual observed for $\mathrm{T}$ waves, namely as if he/she had an 'event' every year. ${ }^{6}$

The index ranges theoretically from 0 , representing the lowest possible concentration scenario (in our case when one experiences only two events at the maximum distance possibly observed for that person) to 1 , representing the highest possible events concentration scenario (in our case when one experiences one event per year with 4 or more episodes occurring every year).

To summarize, our Concentration Index (CI) innovatively includes not only the overall number of critical life events ever experienced and their possible non-linear cumulative effect, but also the yearly distance between them and the number of episodes involved each year. CI is a holistic measure of concentration of events over the life course where positive and negative events are taken into consideration at the same time. The CI can be extended in different ways according to specific research questions or sociological theory to test. For example, it is possible to give different weights to different type of events, it can be calculated on one given life domain at the time, the number of years of recovery between events can be included, and so on. Going through all possible extensions of the index goes well beyond of the scope of the present study. However, we conducted robustness checks utilizing more

\footnotetext{
${ }^{4}$ In the original formulation of the index, the weights measured the fraction of months in a given year spent in poverty or unemployment (Mendola et al. 2011, Busetta et al. 2012).

${ }^{5}$ In our sample, only in rare cases $(0.65 \%$ of cases $)$ we observed more than four episodes per year. For ease of simplicity, to calculate the average share of episodes we top-coded the maximum possible number of episodes per year to four.

${ }^{6}$ For a more detailed graphical illustration of the index, interested readers can refer to Busetta et al. (2019).
} 
complex versions of the index and results are qualitatively similar, at least in our sample (results available upon request).

\section{Method}

We use linear OLS models to test the association between the Concentration Index (CI) and life satisfaction later in life. More recent events tend to have a larger impact on life satisfaction. Since we observe individuals of different ages, younger people with shorter trajectories observed would have had more recent events and less events in total. Subjective wellbeing also notably varies over the life course (Barbuscia and Comolli, 2021). For these reasons, in the models we control for the age of the individual when wellbeing is measured, and the time elapsed since last event. Additional controls are gender, being born in Switzerland and the level of education (primary or lower secondary, upper secondary, tertiary) (Table A.2). Finally, the experience of given events, their number and concentration in time may be endogenous to pre-trajectory's subjective wellbeing levels. Unfortunately, we do not observe life satisfaction before the trajectory of events. However, we dispose of proxies of pre-trajectory wellbeing: namely, the experience of mental health issues and the family living arrangement of respondents at age 15 , both retrieved from the calendar. While not completely solving the issue of reverse causality, these variables represents strong determinants of adolescent wellbeing and we are confident that, together, they constitute a quite robust proxy for it (Comolli et al. 2021).

First, we measure the association between the Concentration Index (CI) and life satisfaction net of the timing of the more recent, the sociodemographic controls and pre-trajectory confounders. Second, we are interested in testing whether events concentrated in particular life stages do have a greater impact on subjective wellbeing, net of how many events actually take place within that life stage and how recently before wellbeing is recorded. To do so, we separate the reported biographies of life events by age-groups: youth (18-29), early adulthood (30-39), midlife (40-49) and older adulthood (50-65) and recalculate the $\mathrm{CI}$ for the events experienced within each age group. We then test for each group the association with life satisfaction measured at the earliest subsequent wave, and no later than five years after the last year reported in the calendar (i.e. before age 35 for the youths, before 45 for the early adults, etc.). As wellbeing is measured in the SHP panel waves of 2014-2017, this age restriction implies that the concentration of critical events is measured for all age groups approximately during the first two decades of the years 2000s. In other words, given that age and period are fixed, due to the wellknown age-period-cohort problem, in this part of the analysis on life-stages we cannot distinguish the effect of cohorts from age.

Results are presented graphically, in terms of predicted life satisfaction by varying lifelong CI, but full models are reported in the Appendix in Tables A.3-A.4. 


\section{Results}

\section{Descriptive results on the concentration of critical events}

The number of 'events' experienced over the life course ranges from 2 to 50 (constrained by the fact that the longest biography retrospectively observed is of 51 years) with an average of ten. The overall number of episodes ranges instead from 2 to 281, with an average of around 15 episodes experienced over the life span considered (Table A.2). Looking year by year, the number of episodes ranges from 0 to 24 but only in $0.65 \%$ of the cases, more than four episodes co-occurring in the same year. Moreover, such co-occurring events are often from different domains: in our case then the number of episodes represents mainly a proxy of the number of different domains involved in episodes occurring each year. Figure 1 shows the simple average frequency of critical events by life domains calculated as number of events in each domain over number of years observed, averaged in the whole sample in Panel (a) and by life stage in Panel (b). In Panel (a) the vertical dash-dotted line corresponds to a frequency of one event every ten years. Health issues and residential moves are the most frequent events in the sample, both happening more frequently than once every decade. Family events on average happen slightly less frequently, while the rarest events are those in the work domain, happening on average around every 20 years. Overall critical events are not very frequent but Panel (b) shows that there are life stage differences. Here the dotted vertical line corresponds to a frequency of one event every five years and the dashed line to a frequency of one event every two years. All kinds of critical events are less frequent in youth, while health issues are much more frequent in midlife and older adulthood (more than one every other year). Work events tend to happen every five years in most age groups while family events tend to happen between every five and every two years, and more frequently in the two oldest age groups.

Mean frequencies though only give a rough idea of the distribution of events in time. Our aim is to test more precisely whether critical events more concentrated in time have a more negative effect on subjective wellbeing compared to events more spaced over the life course ${ }^{7}$. To this end, we adopt a more precise measure of lifetime concentration of critical events, the Concentration Index (CI).

\footnotetext{
${ }^{7}$ As illustrated by Thomas (2018), it is possible that one event prompted another event, although their close proximity in time could also be coincidental; we could not determine the exact reasons for their time proximity. However, regardless of the reason of coincidence, the fact remains that individuals were subject to the effects of both events within a very short time period.
} 
Figure 1: Mean frequency of occurrence of episodes by domain and life stage.

(a)

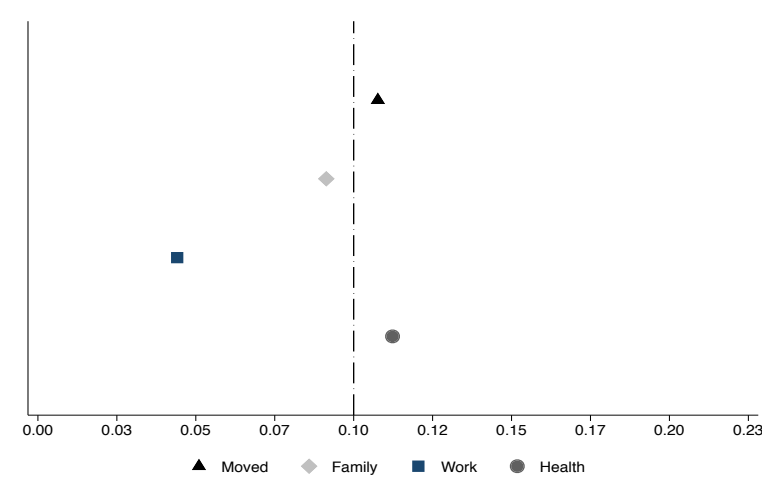

Source: Authors' elaboration based on SHP 2013 biographical data. (b)
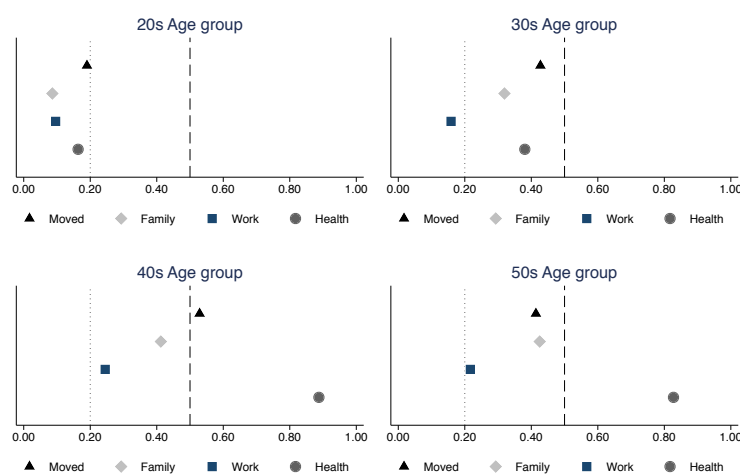

In our analytic sample, the CI ranges from 0.0002 to 0.809 . Figure 2 plots the time varying number of critical events occurring by age for four respondents with different CIs, two extreme profiles: one with very low $\mathrm{CI}$ of 0.0003 and one with very high $\mathrm{CI}$ of 0.808 , and two middle range profiles: CIs of 0.077 and 0.177 . The two extreme profiles show that the lowest concentration represents individuals with very few events happening sparsely in time: in the example given the first event happens around the age of 20 and the second around the age of 28 . The respondent with the highest concentration experiences over 30 events in the life course of 50 years observed and basically one event per year. The two middle profiles show intermediate profiles.

Additionally, Table 1 reports the descriptive statistics of interesting variables comparing individuals with very low CI (bottom 10\%: <0.0063) and very high CI (top 10\%: >0.1453). The high CI group experiences six times the number of events and almost ten times as many episodes than the low CI group and the last event occurs much more recently. The high concentration group includes a larger share of women than the low concentration, slightly younger respondents, but the two groups display similar distributions in terms of educational level.

Finally, Table 2 illustrates the distribution of events by domain in the whole sample and by life stages. While health issues prevail during midlife and older adulthood, during youth it is residential moves the most common type of event while during early adulthood family events are the most common. Years with episodes in more than one domain are more frequent in the two youngest groups, and no one in the oldest age groups experience a year with episodes in all four domains, differences however do not seem large. 
Figure 2: Events-age profiles of respondents with different life course CI

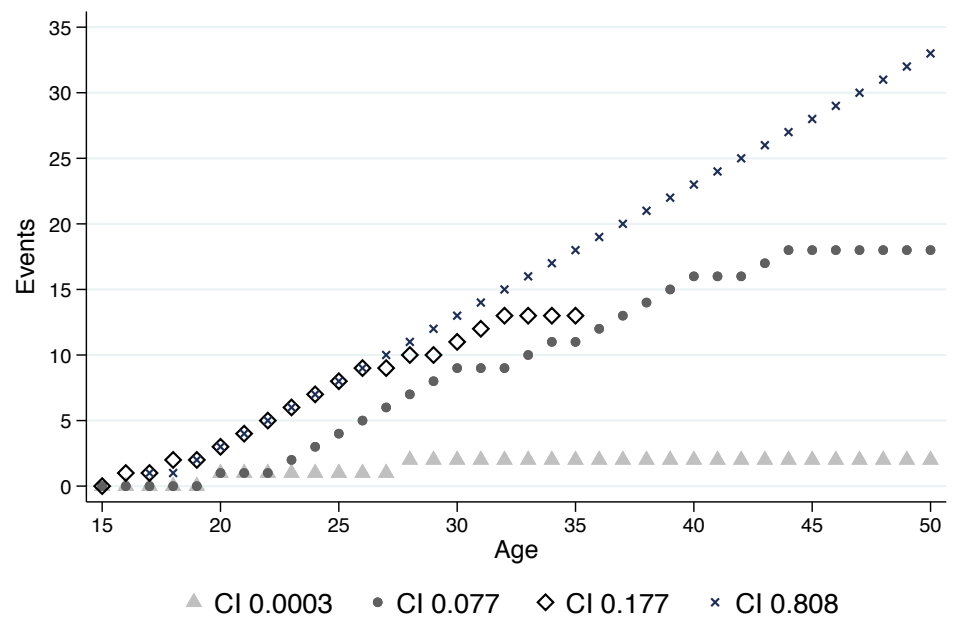

Source: Authors' elaboration based on SHP 2013 biographical data.

Table 1: Descriptive statistics for very low and very high Concentration Index individuals.

Low CI $(<0.0063)$

High CI (>0.1453)

\begin{tabular}{|c|c|c|c|c|c|c|c|c|c|c|}
\hline Variable & $\mathbf{N}$ & Mean & Std. Dev. & Min & $\operatorname{Max}$ & $\mathbf{N}$ & Mean & Std. Dev. & Min & Max \\
\hline Total number of 'events' & 320 & 3.678 & 1.257 & 2 & 7 & 320 & 22.788 & 10.02 & 2 & 50 \\
\hline Total number of episodes & 320 & 4.231 & 1.637 & 2 & 9 & 320 & 41.616 & 29.191 & 3 & 281 \\
\hline Time since last event & 320 & 8.834 & 7.466 & 1 & 39 & 320 & 1.819 & 1.334 & 1 & 16 \\
\hline Age & 320 & 48.056 & 10.773 & 21 & 65 & 320 & 44.794 & 11.448 & 18 & 65 \\
\hline Variable & $\mathbf{N}$ & $\%$ & & & & $\mathbf{N}$ & $\%$ & & & \\
\hline \multicolumn{11}{|l|}{ Gender } \\
\hline Men & 167 & 52.19 & & & & 114 & 35.62 & & & \\
\hline Women & 153 & 47.81 & & & & 206 & 64.38 & & & \\
\hline Total & 320 & 100.00 & & & & 320 & 100.00 & & & \\
\hline \multicolumn{11}{|l|}{ Education } \\
\hline Primary or Lower Secondary & 29 & 9.06 & & & & 32 & 10.00 & & & \\
\hline Upper Secondary & 186 & 58.13 & & & & 181 & 56.56 & & & \\
\hline Tertiary & 105 & 32.81 & & & & 107 & 33.44 & & & \\
\hline Total & 320 & 100.00 & & & & 320 & 100.00 & & & \\
\hline
\end{tabular}

Source: Authors' elaboration based on SHP 2013 biographical data. Note: age and education are measured at the time when subjective wellbeing is measured.

Table 2: Number of 'events' by domain and age groups

\begin{tabular}{rrrrrrrrrrr}
\hline & $\mathbf{1 8 - 2 9}$ & \multicolumn{3}{c}{$\mathbf{3 0 - 3 9}$} & $\mathbf{4 0 - 4 9}$ & $\mathbf{5 0 - 6 5}$ & \multicolumn{2}{c}{ All } \\
& $\mathbf{N}$ & $\mathbf{\%}$ & $\mathbf{N}$ & $\mathbf{\%}$ & $\mathbf{N}$ & $\mathbf{\%}$ & $\mathbf{N}$ & $\mathbf{\%}$ & $\mathbf{N}$ & $\mathbf{\%}$ \\
\hline Health issues & 5816 & 19,32 & 4736 & 28,12 & 4386 & 50,76 & 5089 & 44,08 & 20027 & 29,83 \\
Residential moves & 12252 & 40,69 & 4416 & 26,22 & 1409 & 16,31 & 798 & 6,91 & 18875 & 28,11 \\
Work & 4397 & 14,60 & 1396 & 8,29 & 732 & 8,47 & 3778 & 32,73 & 10303 & 15,35 \\
Family & 7645 & 25,39 & 6294 & 37,37 & 2113 & 24,46 & 1879 & 16,28 & 17931 & 26,71 \\
\hline & 30110 & 100 & 16842 & 100 & 8640 & 100 & 11544 & 100 & 67136 & 100 \\
\hline
\end{tabular}

Source: Authors' elaboration based on SHP 2013 biographical data.

The association between $C I$ and SWB. Multivariate Results.

Figure 3 illustrates the association between lifelong concentration (CI) and life satisfaction (see Models 1-2 in Table A.3). In support of our first hypothesis, our results show that - net of socio-demographic characteristics and pre-trajectory (before age 15) determinants of wellbeing and time since the last of these events - the index of concentration of such critical events over the life course is negatively 
associated to life satisfaction. The higher the CI, the stronger is the longstanding negative effect on wellbeing. Neither more proximal determinants nor pre-trajectory proxies of subjective wellbeing affect the association between $\mathrm{CI}$ and life satisfaction. The point estimate suggests an association around -0.3 for a 0.1 increase in CI (Table A.3). Taking as an example the event-age profiles of the two middle respondents plotted earlier in Figure 2: the respondent with a CI of 0.177 reports a 0.3 points lower life satisfaction relative to the respondent with a $0.077 \mathrm{CI}$. The magnitude of the coefficient is sizable, as it is similar for instance to the association between socioeconomic status (country of birth or education, Table A.3) and subjective wellbeing. The association between the CI and life satisfaction does not seem to depend on how recently the last event has been experienced (Models 3-5 in Table A.3).

\section{Figure 3: Predicted Life Satisfaction by Concentration Index (CI).}

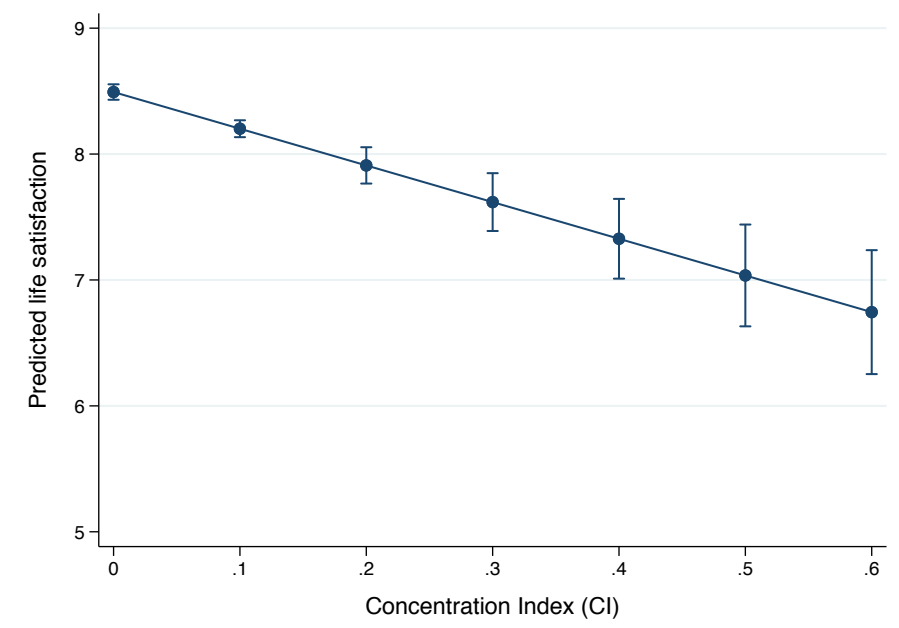

Source: Authors' elaboration based on SHP 2013 biographical data and 2014-2017 SHP panel data. Note: Robust standard errors. Models control for time since the last event, gender, age and educational level at the time of measuring SWB, being born in Switzerland and pre-trajectory mental issues and living arrangement at age 15 . See Table A.3 for full models.

To test whether events concentrated in usually less densely populated life phases have a greater impact on subjective wellbeing, we recalculate the Concentration Index (CI) in youth (18-29), early adulthood (30-39), midlife (40-49) and older adulthood (50-65). Subjective wellbeing is measured at earliest subsequent age and no later than five years after each trajectory. Figure 4 and Table A. 4 show that the strength of the negative association between the life course CI and subjective wellbeing depends on the life stage during which the episodes occur, but a higher critical events' concentration is associated to a significantly lower life satisfaction in all life stages. The association is stronger in the youngest (20s) and oldest (50s) groups, and smallest in the early adulthood (30s) group. The association remains significant net of sociodemographic characteristics and pre-trajectory determinants of wellbeing.

Life stages' differences, though not large, might be driven by the fact that in early adulthood the occurrence of multiple transitions is more normative than in other life stages, thus the concentration of 
critical events during the 30 s is less detrimental for SWB than concentrated events in other stages in the life course. However, we cannot rule out the possibility that the concentration of some types of events, more frequent in certain phases of life than others, is more negatively related to SWB than the concentration of different types of events. For instance, in older age groups, the stronger impact of concentration of events might be due to the much more frequent health problems, as shown earlier (Table 2). Another possible explanation is the heterogeneity in the CI within age groups. Those in their 20s reported not only a smaller concentration (mean value of CI of 0.0782 ) but also a smaller heterogeneity ( $\mathrm{sd}$ of 0.10 ) while those in their 50 experienced more co-occurrent events - mean value of CI of 0.12 - and higher heterogeneity (sd of 0.144 )

\section{Figure 4: Predicted Life Satisfaction by life course Concentration Index (CI) by life stage.}
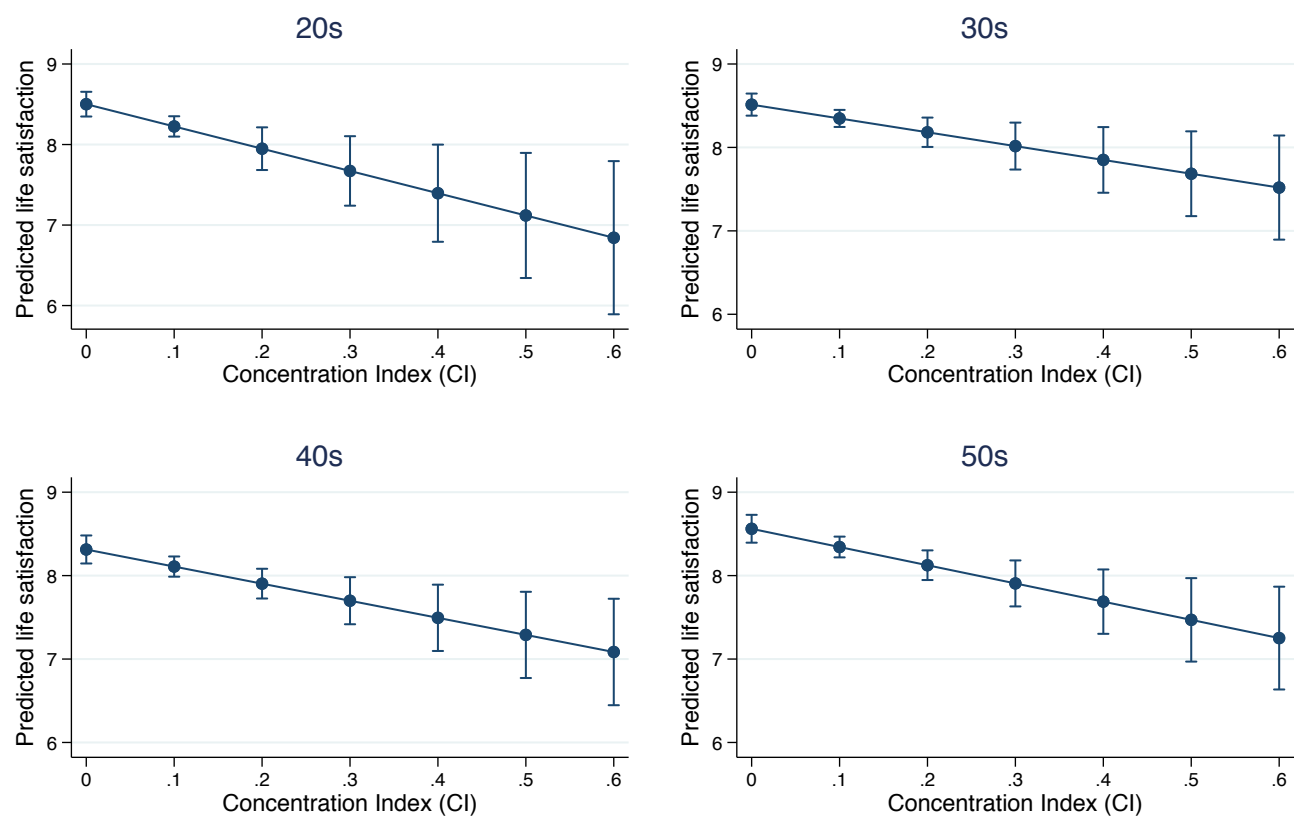

Source: Authors' elaboration based on SHP 2013 biographical data and 2014-2017 SHP panel data. Note: Robust standard errors. For each group life satisfaction is measured at the earliest subsequent wave, and no later than five years after the last year reported in the calendar (i.e. before age 35 for the youths, before 45 for the early adults, etc.). Models control for time since the last event, gender, age and educational level at the time of measuring SWB, being born in Switzerland and pre-trajectory mental issues and living arrangement at age 15. See Table A.4 for full models.

We conducted a number of robustness checks to ensure the soundness of our estimates (Table A.5). First, if we include in the index a term, $o_{j k}$, to account for the number of years without any events (length recovery period), results remain identical ${ }^{8}$ (Models 1-2). Second, qualitatively similar results are also obtained if we explicitly add a term in the index that accounts for the recentness of events, instead of controlling for the time since the last event in our models. Following Busetta and colleagues (2019), we added a recentness factor $r e$, increasing the smaller the time since the latest events. This factor is inserted in the CI as an additive term and its relevance with respect to the main term of the

${ }^{8}$ This version of the index is calculated as: $C I_{i}=\frac{\sum_{j, k}\left(d_{j k}+1\right)^{-\left(o_{j k}+1\right)} w_{j k}}{\sum_{g=1}^{T-1} \frac{g}{T-g+1}}, j>k$. 
index as in Eq. (1) is weighted choosing a discretionary alpha level ${ }^{9}$. Models 3-4 in Table A.5 show that at different levels of alpha, the index remains negatively correlated with SWB. We preferred the simpler specification without the re factor as it depends less on the researcher's discretional choice and it gives a simpler interpretation of the CI, but results are unaltered by this choice. Third, controlling for pre-trajectories physical health (illnesses, operations and accidents) instead of mental health leaves results unaltered (Model 5). Finally, strong gender differences do not emerge (not shown), therefore, for the sake of brevity we do not distinguish results by gender.

\section{Discussion}

Individuals experience a variety of critical events during their life course. A rich literature documents that subjective wellbeing (SWB) is influenced by such critical events (Yap et al., 2014; Hentschel et al., 2017) but, most existing studies focus on one single event or at best multiple events in a single life domain at the time (Booker and Saker, 2011; Demey et al., 2014). Yet, the principle of the multidimensionality of the life course and the stress proliferation theory posit that events do not occur in isolation but the exposure to one stressor may lead to exposure to other stressors involving multiple life domains and generating periods in the life course particularly crowded of critical events.

The relatively few studies on this topic have focused more on the evolution over time of SWB, in terms of processes of anticipation, adaptation, and recovery (Luhmann and Eid 2009; Voelkle et al 2013; Anusic et al 2014; Luhmann et al 2014) simply counting the number of events experienced in a period of time (Wheaton and Clarke 2003; Seery et al. 2010; Frijters et al. 2020) as a measure of concentration of events. The present study aimed to fill the gaps in the existing literature acknowledging not only that multiple events might happen at the same time or in close temporal proximity, but also that the distribution of critical life course events across time, i.e., what we called the concentration of events, might accentuate changes in SWB. We argue that life phases densely populated of critical events may cause an extremely acute resource drain and affect wellbeing more strongly, and more persistently over time, than whether the same events were sparsely distributed.

The first contribution of this study is that we are able to assess more rigorously than just counting the number of events the impact of lifetime concentration of critical events on SWB (McMahon et al. 2003; Seery et al. 2010). We introduce on a novel indicator of the distribution of events in individuals' history, the Concentration Index, that considers not only, as in previous studies, the overall number of events ever experienced but also the time between them and the number of different domains and occurrences involved at each time. Our main finding is that the CI of life course critical events is negatively associated to life satisfaction. Crucially, this holds not only net of socio-demographic characteristics

\footnotetext{
${ }^{9}$ This version of the index is calculated as: $C I_{i}=\alpha \frac{\sum_{j, k}\left(d_{j k}+1\right)^{-1} w_{j k}}{\sum_{g=1}^{T-1} \frac{g}{T-g+1}}+(1-\alpha) r e, j>k$.
} 
and pre-trajectory (before age 15) determinants of wellbeing, but it matters also beyond the recentness of the experience of the last of these events. Then, the wellbeing responds differently according to the spacing between events and not simply to the number of events experienced.

The second contribution to the literature is that we empirically investigate whether the relationship between the concentration of events and SWB holds in all phases of the adult life course (youth and early adulthood, midlife and older adulthood).

We find that a higher critical events' concentration is associated to a significantly lower life satisfaction, net of sociodemographic characteristics and pre-trajectory determinants of wellbeing, in all life stages. Yet, the strength of the association between the life course CI and SWB varies across the life stage during which the episodes occur. Early adults in their thirties seems less severely affected by the concentration of critical events they experience. The fact that the concentration of critical events during the 30s is less detrimental for SWB than concentrated events early or later on in the life course might be driven by the fact that during early adulthood multiple transitions are more frequent and more normative compared to youth, midlife and older adulthood. When experiencing a crowded period of critical events in a life stage when those are not expected, their destabilizing effect on SWB might be stronger. However, we cannot rule out the alternative explanation that the concentration of some kind of events, more frequent in certain phases of life than others, is more negatively related to SWB than the concentration of different types of events. For instance, in older age groups, the strongest impact of concentration of events might be due to the more frequent health problems compared to family or work events. If the concentration of health events is more strongly associated to SWB than the concentration of family or work critical events, this would explain the more negative association found during older compared to early adulthood.

Finally, our findings cumulate with findings from earlier studies speaking in favour of combining critical events with opposite valence and more or less consequential with each other, especially in the context of assessing life-long adversities and the related long-term effects on wellbeing (Seery et al., 2010; Luhmann et al., 2014).

Our study suffers from a few limitations. First, using a life course index to summaries lifelong trajectories of critical events clearly reduces our chances of identifying the mechanisms explaining the relationship between critical events concentration over time and SWB. Second, despite controlling for pre-trajectory determinants of SWB, we do not have information on SWB during adolescence or before the first critical event is observed. To estimate the causal effect of the CI on SWB we would need to control for that, in order to rule out the possibility that happier individuals to start with, tend to experience, not only less critical events, but also less concentrated events. Third, the small number of observations prevent us from investigating potential heterogeneities in the effects of the CI on SWB for instance across individuals' socioeconomic background. We investigate possible heterogeneities across gender which do not yield significant differences. 
Despite these limitations, our study represents an important contribution to the literature, being the first to assess how lifetime concentration of critical events in a relatively crowded life course section lowers subjective wellbeing later in life, especially during youth and older adulthood. It is important to stress that the effect of a higher critical events' concentration on life satisfaction is not simply a reflection of the number of critical events a person experience, but that the dispersion of such events over time matters in and of itself. 


\section{References}

Aassve, A., Goisis, A., \& Sironi, M. (2012). Happiness and childbearing across Europe. Social indicators research, 108(1), 65-86.

Anusic, I., Yap, S. C., \& Lucas, R. E. (2014). Testing set-point theory in a Swiss national sample: Reaction and adaptation to major life events. Social indicators research, 119(3), 1265-1288.

Busetta, A., Mendola, D., \& Vignoli, D. (2019). Persistent joblessness and fertility intentions. Demographic Research, 40 , 185-218.

Charles, K. K., \& Stephens, Jr, M. (2004). Job displacement, disability, and divorce. Journal of Labor Economics, 22(2), 489522.

Clark, W. A. (2016). Life events and moves under duress: disruption in the life course and mobility outcomes. Longitudinal and Life Course Studies, 7(3), 218-239.

Clarke, P., \& Wheaton, B. (2004) Mapping social context on mental health trajectories through adulthood. In: R. Macmillan (Ed.), Structure of the life course: Standardized? Individualized? Differentiated ? Advances in Life Course Research (Vol. 9, pp. 269-301). Amsterdam: Elsevier.

Dannefer, D. (2018) Systemic and Reflexive: Foundations of Cumulative Dis/Advantage and Life-Course Processes, The Journals of Gerontology: Series B.

Demey, D., Berrington, A., Evandrou, M., \& Falkingham, J. (2014). Living alone and psychological well-being in mid-life: does partnership history matter?. J Epidemiol Community Health, 68(5), 403-410.

Dienstbier, R. A. (1989). Arousal and physiological toughness: Implications for mental and physical health. Psychological Review, 96(1), 84-100.

Dienstbier, R. A. (1992). Mutual impacts of toughening on crises and losses. Life crises and experiences of loss in adulthood, 367-384.

Diewald, M., and Mayer, K. U. (2009). The sociology of the life course and life span psychology: Integrated paradigm or complementing pathways? Advances in Life Course Research, 14(1-2), 5-14.

DiPrete, T. A., and Eirich, G. M. (2006). Cumulative Advantage as a Mechanism for Inequality: A Review of Theoretical and Empirical Developments. Annual Review of Sociology, 32, 271-297.

disability. Social Psychiatry and Psychiatric Epidemiology, 42, 24-28.

Dohrenwend, B. P. (2006). Inventorying stressful life events as risk factors for psychopathology: Toward resolution of the problem of intracategory variability. Psychological bulletin, 132(3), 477.

Dohrenwend, B. S., \& Dohrenwend, B. P. (1974). Stressful life events: Their nature and effects. John Wiley \& Sons.

Frijters, P., Krekel, C., \& Ulker, A. (2020). Machiavelli versus Concave Utility Functions: Should Bads Be Spread out or Concentrated? (No. 13021). IZA Discussion Papers.

Hentschel, S., Eid, M., \& Kutscher, T. (2017). The influence of major life events and personality traits on the stability of affective well-being. Journal of Happiness Studies, 18(3), 719-741.

Hopson, B., \& Adams, J. (1976). Towards an understanding of transition: Defining some boundaries of transition dynamics. Transition: Understanding and managing personal change, 3-25.

Kessler, R. C., Davis, C. G., \& Kendler, K. S. (1997). Childhood adversity and adult psychiatric disorder in the US National Comorbidity Survey. Psychological medicine, 27(5), 1101-1119.

Kettlewell, N., Morris, R. W., Ho, N., Cobb-Clark, D. A., Cripps, S., \& Glozier, N. (2020). The differential impact of major life events on cognitive and affective wellbeing. SSM-population health, 10, 100533.

Lindeboom, M., Portrait, F., \& Van den Berg, G. J. (2002). An econometric analysis of the mental-health effects of major events in the life of older individuals. Health economics, 11(6), 505-520.

Longua, J., DeHart, T., Tennen, H., \& Armeli, S. (2009). Personality moderates the interaction between positive and negative daily events predicting negative affect and stress. Journal of Research in Personality, 43(4), 547-555

Luhmann, M., \& Eid, M. (2009). Does it really feel the same? Changes in life satisfaction following repeated life events. Journal of personality and social psychology, 97(2), 363.

Luhmann, M., Hofmann, W., Eid, M., \& Lucas, R. E. (2012). Subjective well-being and adaptation to life events: a metaanalysis. Journal of personality and social psychology, 102(3), 592.

Luhmann, M., Orth, U., Specht, J., Kandler, C., \& Lucas, R. E. (2014). Studying changes in life circumstances and personality: It's about time. European Journal of Personality, 28(3), 256-266.

McCullough, G., Huebner, E. S., \& Laughlin, J. E. (2000). Life events, self-concept, and adolescent's positive subjective wellbeing.

Mendola, D., \& Busetta, A. (2012). The Importance of Consecutive Spells of Poverty: A Path-Dependent Index of Longitudinal Poverty. Review of income and wealth, 58(2), 355-374.

Mendola, D., Busetta, A., \& Milito, A. M. (2011). Combining the intensity and sequencing of the poverty experience: a class of longitudinal poverty indices. Journal of the Royal Statistical Society: Series A (Statistics in Society), 174(4), 953-973.

Myrskylä, M., \& Margolis, R. (2014). Happiness: Before and after the kids. Demography, 51(5), 1843-1866. 
Nezlek, J. B., \& Plesko, R. M. (2003). Affect and self-based models of the relationships between daily events and daily wellbeing. Personality and Social Psychology Bulletin, 29, 584-596.

O'Rand, A. M. (1996). The precious and the precocious: Understanding cumulative disadvantage and cumulative advantage over the life course. The Gerontologist, 36(2), 230-238.

Park, C. L. (2010). Making sense of the meaning literature: an integrative review of meaning making and its effects on adjustment to stressful life events. Psychological bulletin, 136(2), 257.

Pearlin, L.I. (2010). The Life Course and the Stress Process: Some Conceptual Comparisons. The Journals of Gerontology Series B: Psychological Sciences and Social Sciences 65(2), 207-215.

Pearlin, L.I., Menaghan, E. G., Lieberman, M. A., and Mullan, J. T. (1981). The stress process. Journal of Health and Social behaviour, 337-356.

Ponomarenko, V. (2016). Cumulative disadvantages of non-employment and non-standard work for career patterns and subjective well-being in retirement. Advances in Life Course Research, 30, 133-148.

Psychology in the Schools, 37, 281-290.

Raposa, E. B., Hammen, C. L., Brennan, P. A., O'Callaghan, F., \& Najman, J. M. (2014). Early adversity and health outcomes in young adulthood: the role of ongoing stress. Health Psychology, 33(5), 410.

Reich, J. W., \& Zautra, A. (1981). Life events and personal causation: Some relationships with satisfaction and distress. Journal of personality and social psychology, 41(5), 1002.

Sayer, L. C., England, P., Allison, P. D., \& Kangas, N. (2011). She left, he left: How employment and satisfaction affect women's and men's decisions to leave marriages. American Journal of Sociology, 116(6), 1982-2018.

Seery, M. D., Holman, E. A., \& Silver, R. C. (2010). Whatever does not kill us: cumulative lifetime adversity, vulnerability, and resilience. Journal of personality and social psychology, 99(6), 1025.

Suh, E., Diener, E., \& Fujita, F. (1996). Events and subjective well-being: Only recent events matter. Journal of Personality and Social Psychology, 70, 1091-1102.

Thoits, P. A. (1983). Multiple identities and psychological well-being: A reformulation and test of the social isolation hypothesis. American Sociological Review, 48, 174-187.

Thomas, J. S. (2018). Dimensions of family disruption: Coincidence, interactions, and impacts on children's educational attainment. Longitudinal and Life Course Studies, 9(2), 157-187.

Tsakanikos, E., Bouras, N., \& Costello, H. (2007). Multiple exposure to life events and clinical psychopathology in adults with intellectual

Turner, R. J., Wheaton, B., \& Lloyd, D. A. (1995). The epidemiology of social stress. American sociological review, 104-125.

Voelkle, M. C., Ebner, N. C., Lindenberger, U., \& Riediger, M. (2013). Here we go again: Anticipatory and reactive mood responses to recurring unpleasant situations throughout adulthood. Emotion, 13(3), 424.

Wheaton, B., \& Clarke, P. (2003). Space meets time: Integrating temporal and contextual influences on mental health in early adulthood. American Sociological Review, 680-706.

Wheaton, B., \& Reid, S. (2008). The role of timing vs. duration in the cumulative work history effects of job exits and nonemployment on women's mental health. Advances in life course research, 13, 195-232.

Yap, S. C., Anusic, I., \& Lucas, R. E. (2014). Does happiness change? Evidence from longitudinal studies. Stability of Happiness, 127-145. 


\section{Appendix}

Table A.1: Tabulation of events

\begin{tabular}{lrr}
\hline Categories of events & $\mathrm{N}$ & $\%$ \\
\hline Health issues & 20,027 & 28.79 \\
Residential moves & 18,875 & 27.13 \\
Own marriage/registered partnership & 10,191 & 14.65 \\
Birth of a child & 8,362 & 12.02 \\
Bereavement (parents/siblings/own children) & 4,717 & 6.78 \\
Retirement & 2,894 & 4.16 \\
Entry into Full time work & 1,417 & 2.04 \\
Own separation/divorce/widowhood & 880 & 1.27 \\
Unemployment & 771 & 1.11 \\
Exit from Full time work -> Part time work & 399 & 0.57 \\
Parental separation/divorce & 353 & 0.51 \\
Exit from Unemployment -> Part time work & 288 & 0.41 \\
Birth of a sibling & 195 & 0.28 \\
Exit from Unemployment -> Employed (no info on activity rate) & 114 & 0.16 \\
Parental marriage/remarriage/partnering & 80 & 0.12 \\
\hline & 69,563 & 100.00 \\
\hline Source: & &
\end{tabular}

Source: elaboration of the authors based on SHP 2013-2018 data.

Table A.2: Summary statistics

\begin{tabular}{|c|c|c|c|c|c|c|}
\hline & & $\mathrm{Obs} / \mathrm{N}$ & Mean $/ \%$ & Std.Dev. & Min & Max \\
\hline Life satisfaction (SWB) & & 3,192 & 8.33 & 1.407 & 0 & 10 \\
\hline Concentration Index $(\mathrm{CI})$ & & 3192 & .051 & .076 & 0 & .809 \\
\hline Total number of events & & 3,192 & 9.87 & 6.769 & 2 & 50 \\
\hline Total number of episodes & & 3,192 & 14.73 & 15.069 & 2 & 281 \\
\hline Years since last events & & 3,192 & 4.86 & 5.01 & 1 & 39 \\
\hline Age at the time of interview & & 3,192 & 46.42 & 11.082 & 18 & 65 \\
\hline \multirow[t]{2}{*}{ Gender } & Male & 1,444 & 45.24 & & & \\
\hline & Female & 1,748 & 54.76 & & & \\
\hline \multirow[t]{3}{*}{$\begin{array}{r}\text { Education at the time of } \\
\text { interview }\end{array}$} & $\begin{array}{r}\text { Primary or low secondary education } \\
\text { (Ref) }\end{array}$ & 207 & 6.48 & & & \\
\hline & Upper Secondary education & 1,702 & 53.32 & & & \\
\hline & Tertiary education & 1,283 & 40.19 & & & \\
\hline \multirow[t]{2}{*}{ Born in Switzerland } & Born in Switzerland & 2,452 & 76.82 & & & \\
\hline & Born abroad & 740 & 23.18 & & & \\
\hline \multirow[t]{2}{*}{ Pre-trajectory mental health } & No mental issues (Ref) & 3,182 & 99.69 & & & \\
\hline & Mental issues before age 15 & 10 & 0.31 & & & \\
\hline \multirow{4}{*}{$\begin{array}{r}\text { Pre-trajectory living } \\
\text { arrangement }\end{array}$} & Lived with both parents & 2,625 & 82.24 & & & \\
\hline & Lived with lone parent & 415 & 13.00 & & & \\
\hline & $\begin{array}{r}\text { Lived alone or other living } \\
\text { arrangement }\end{array}$ & 117 & 3.67 & & & \\
\hline & Missing living arrangement & 35 & 1.10 & & & \\
\hline
\end{tabular}


Table A.3: Linear OLS model of subjective wellbeing.

\begin{tabular}{|c|c|c|c|c|c|}
\hline & $\begin{array}{l}\text { Model } \\
\text { (1) }\end{array}$ & $\begin{array}{l}\text { Model } \\
(2)\end{array}$ & $\begin{array}{l}\text { Model } \\
\text { (3) }\end{array}$ & $\begin{array}{l}\text { Model } \\
(4) \\
\end{array}$ & $\begin{array}{l}\text { Model } \\
(5)\end{array}$ \\
\hline Concentration Index (CI) & $-3.187 * * *$ & $-3.138 * * *$ & $-2.913 * * *$ & $-2.905 * * *$ & $-3.078 * * *$ \\
\hline Time since last event & $(-4.040--2.335)$ & $(-3.995--2.282)$ & $\begin{array}{c}(-3.797--2.030) \\
0.013 * * * \\
(0.005-0.022)\end{array}$ & $(-3.794--2.016)$ & $(-4.050--2.105)$ \\
\hline \multicolumn{6}{|l|}{ Last event in the last 2 years (Ref) } \\
\hline Last event $3-5$ years ago & & & & $\begin{array}{c}0.034 \\
(-0.085-0.153)\end{array}$ & $\begin{array}{c}0.068 \\
(-0.057-0.192)\end{array}$ \\
\hline Last event 6 years ago or earlier & & & & $\begin{array}{c}0.155 * * * \\
(0.039-0.270)\end{array}$ & $\begin{array}{c}0.143^{*} \\
(-0.017-0.304)\end{array}$ \\
\hline Last event $3-5$ years ago*CI & & & & & $\begin{array}{c}2.178 \\
(-0.419-4.774)\end{array}$ \\
\hline Last event 6 years ago or earlier*CI & & & & & $\begin{array}{c}0.019 \\
(-3.702-3.739)\end{array}$ \\
\hline Age (18-65) & $\begin{array}{c}0.005^{* *} \\
(0.001-0.009)\end{array}$ & $\begin{array}{c}0.004^{*} \\
(-0.000-0.008)\end{array}$ & $\begin{array}{c}0.003 \\
(-0.002-0.007)\end{array}$ & $\begin{array}{c}0.003 \\
(-0.001-0.007)\end{array}$ & $\begin{array}{c}0.003 \\
(-0.001-0.008)\end{array}$ \\
\hline \multicolumn{6}{|l|}{ Men (Ref) } \\
\hline Woman & $\begin{array}{c}0.106^{* *} \\
(0.008-0.204)\end{array}$ & $\begin{array}{c}0.102^{* *} \\
(0.004-0.200)\end{array}$ & $\begin{array}{c}0.098^{* *} \\
(0.000-0.196)\end{array}$ & $\begin{array}{c}0.101^{* *} \\
(0.003-0.199)\end{array}$ & $\begin{array}{c}0.099 * * \\
(0.001-0.197)\end{array}$ \\
\hline \multicolumn{6}{|l|}{ Born in Switzerland (Ref) } \\
\hline Not Born in Switzerland & $\begin{array}{c}-0.256^{* * *} \\
(-0.386--0.126)\end{array}$ & $\begin{array}{c}-0.258 * * * \\
(-0.389--0.128)\end{array}$ & $\begin{array}{c}-0.257 * * * \\
(-0.387--0.127)\end{array}$ & $\begin{array}{c}-0.260 * * * \\
(-0.391--0.130)\end{array}$ & $\begin{array}{c}-0.261 * * * \\
(-0.391--0.130)\end{array}$ \\
\hline \multicolumn{6}{|l|}{ Primary or low secondary education (Ref) } \\
\hline Upper Secondary education & $\begin{array}{c}0.398 * * * \\
(0.122-0.675)\end{array}$ & $\begin{array}{c}0.376^{* * *} \\
(0.102-0.651)\end{array}$ & $\begin{array}{c}0.378 * * * \\
(0.104-0.653)\end{array}$ & $\begin{array}{c}0.374 * * * \\
(0.099-0.648)\end{array}$ & $\begin{array}{c}0.379 * * * \\
(0.105-0.654)\end{array}$ \\
\hline Tertiary education & $\begin{array}{c}0.484 * * * \\
(0.207-0.760)\end{array}$ & $\begin{array}{c}0.462 * * * \\
(0.187-0.737)\end{array}$ & $\begin{array}{c}0.467 * * * \\
(0.192-0.742)\end{array}$ & $\begin{array}{c}0.458^{* * *} \\
(0.183-0.733)\end{array}$ & $\begin{array}{c}0.461 * * * \\
(0.186-0.736)\end{array}$ \\
\hline \multicolumn{6}{|l|}{ No mental issues (Ref) } \\
\hline Mental issues before age 15 & & $\begin{array}{c}-0.364 \\
(-1.513-0.785)\end{array}$ & $\begin{array}{c}-0.387 \\
(-1.536-0.762)\end{array}$ & $\begin{array}{c}-0.390 \\
(-1.533-0.754)\end{array}$ & $\begin{array}{c}-0.479 \\
(-1.652-0.693)\end{array}$ \\
\hline \multicolumn{6}{|l|}{ Lived with both parents (Ref) } \\
\hline Lived with lone parent & & $\begin{array}{c}-0.178^{* *} \\
(-0.341--0.015)\end{array}$ & $\begin{array}{c}-0.175 * * \\
(-0.338--0.013)\end{array}$ & $\begin{array}{c}-0.174 * * \\
(-0.337--0.012)\end{array}$ & $\begin{array}{c}-0.176^{* *} \\
(-0.339--0.014)\end{array}$ \\
\hline Lived alone or other living arrangement & & $\begin{array}{c}0.109 \\
(-0.132-0.349)\end{array}$ & $\begin{array}{c}0.109 \\
(-0.132-0.351)\end{array}$ & $\begin{array}{c}0.111 \\
(-0.131-0.354)\end{array}$ & $\begin{array}{c}0.104 \\
(-0.139-0.347)\end{array}$ \\
\hline Missing living arrangement & & $\begin{array}{c}-0.013 \\
(-0.418-0.392)\end{array}$ & $\begin{array}{c}0.003 \\
(-0.401-0.407)\end{array}$ & $\begin{array}{c}0.009 \\
(-0.399-0.417)\end{array}$ & $\begin{array}{c}0.012 \\
(-0.396-0.421)\end{array}$ \\
\hline Constant & $\begin{array}{c}7.922 * * * \\
(7.639-8.205)\end{array}$ & $\begin{array}{c}7.965 * * * \\
(7.683-8.248)\end{array}$ & $\begin{array}{c}7.898^{* * *} \\
(7.611-8.185)\end{array}$ & $\begin{array}{c}7.916^{* * * *} \\
(7.628-8.205)\end{array}$ & $\begin{array}{c}7.920 * * * \\
(7.631-8.208)\end{array}$ \\
\hline Observations & 3,192 & 3,192 & 3,192 & 3,192 & 3,192 \\
\hline R-squared & 0.049 & 0.051 & 0.053 & 0.053 & 0.054 \\
\hline
\end{tabular}

Source: Authors' elaboration based on SHP 2013-2018 data. Note: year, age and education are measured at the time when subjective wellbeing is measured. 
Table A.4: Linear OLS model of subjective wellbeing, by life stage.

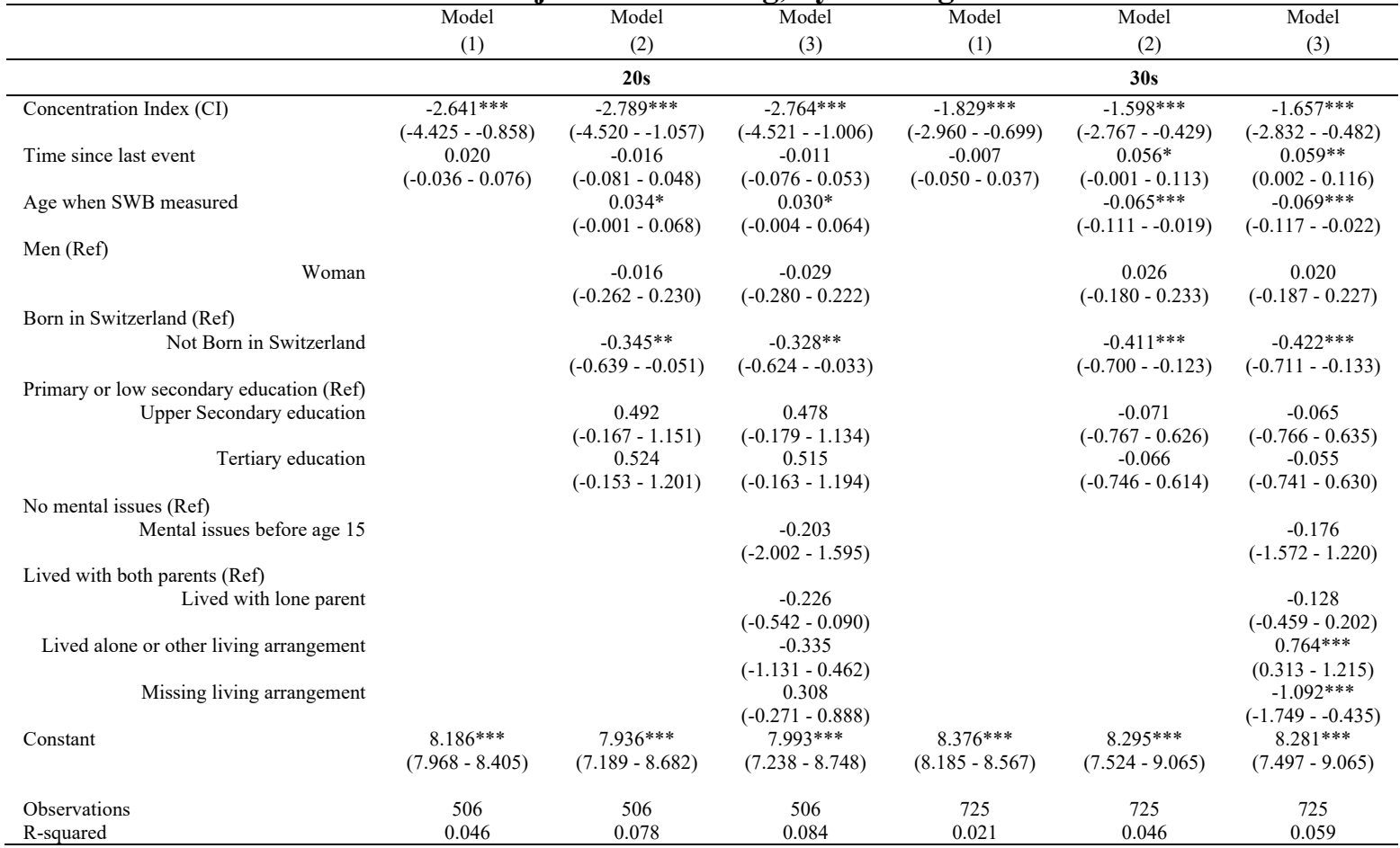

Source: Authors' elaboration based on SHP 2013-2018 data. Note: year, age and education are measured at the time when subjective wellbeing is measured.

Table A.4 (Cont'd): Linear OLS model of subjective wellbeing, by life stage.

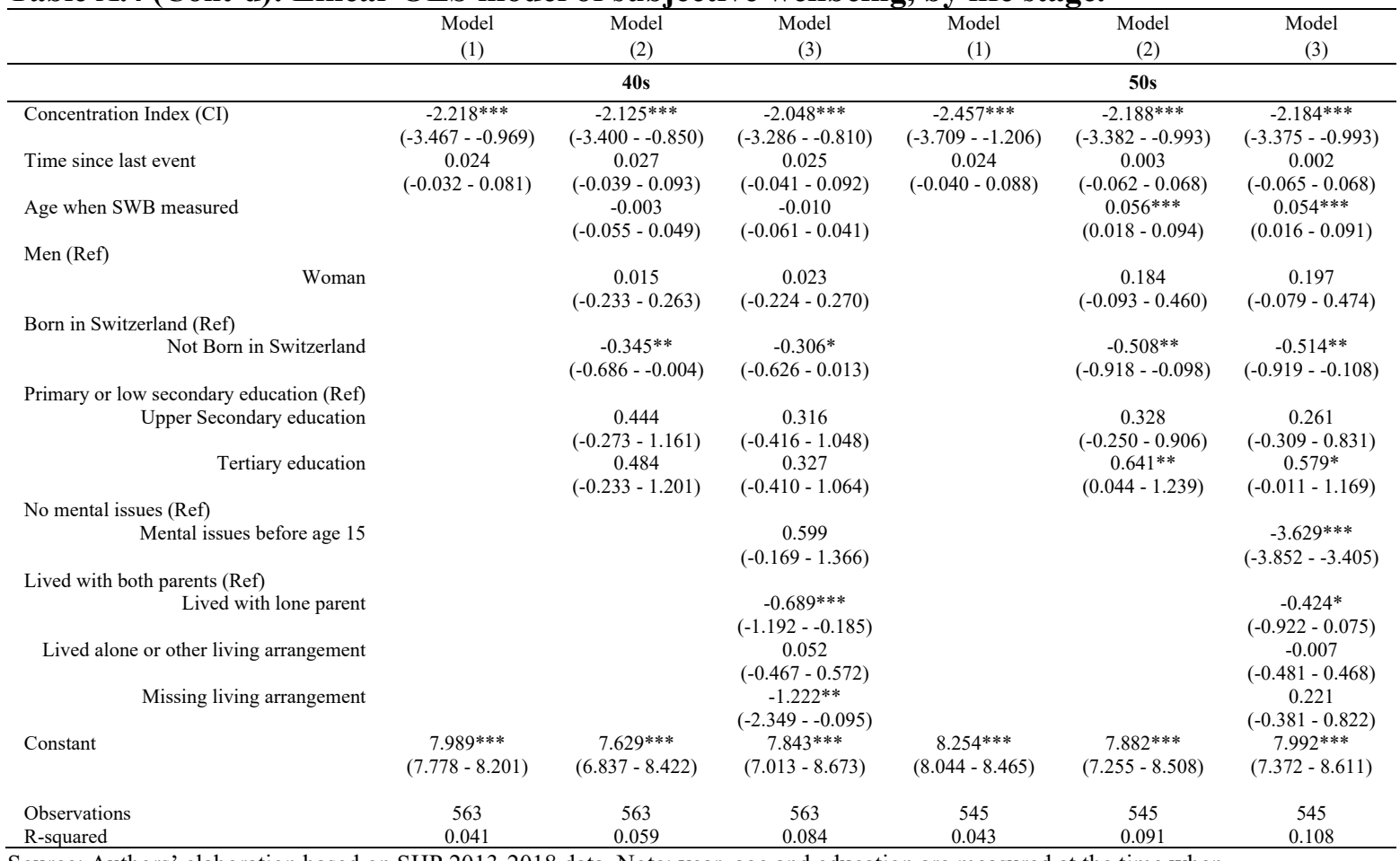

Source: Authors' elaboration based on SHP 2013-2018 data. Note: year, age and education are measured at the time when subjective wellbeing is measured. 
Table A.5: Robustness checks.

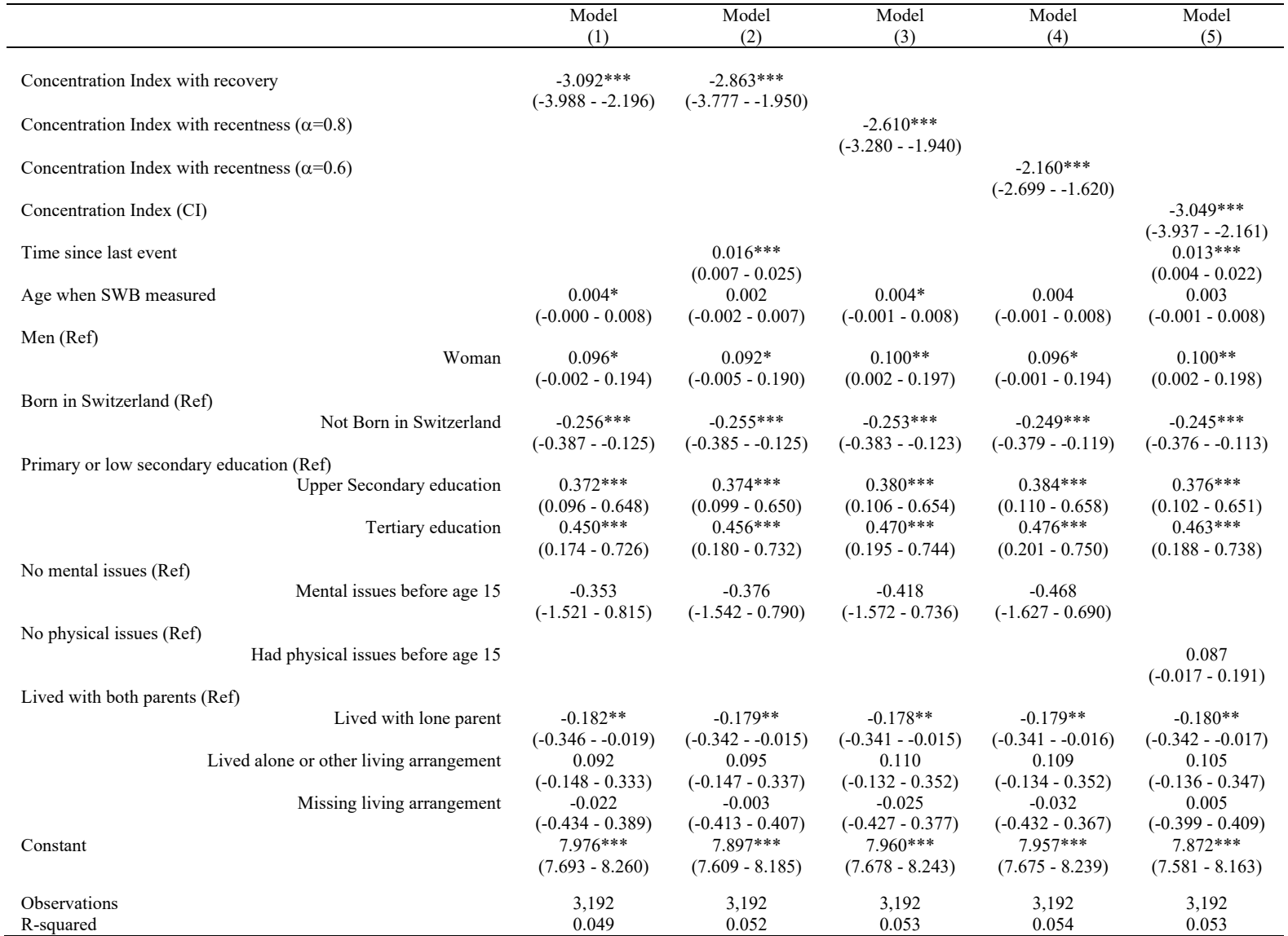

Source: Authors' elaboration based on SHP 2013-2018 data. Note: year, age and education are measured at the time when subjective wellbeing is measured. 